\title{
New product development
}

Kaye, Steve

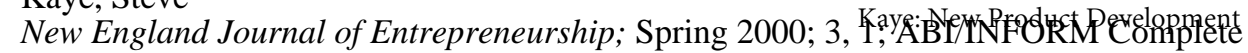

pg. 9

\section{New Product Development}

\author{
Steve Kaye \\ President, Steve Kaye New Products, Inc.
}

$E$ ditor's Note: Based on our own experience, we know most companies have a new product "process." The process usually involves a "system" for idea generation and a methodology to test and refine the ideas. Typical consumer products can take years to develop and can cost hundreds of thousands of dollars. Technical products can take much longer.

Despite these processes and systems, most new products and services fail in the marketplace. Historically, over 90 percent of new products fail. This is a miserable batting average. It is a tragedy and it means that the traditional new product process is really broken. It is slow, costly, and produces mediocre products that fail. Unfortunately, most entrepreneurs try to use the big company process, or hire consultants who coach them on these processes.

The editors of NEJE decided to interview Steve Kaye, president of Steve Kaye New Products, Inc. (www.stevekayenewproducts.com), of Westport, Connecticut. His organization, founded in 1977, specializes in creating new products and services and restaging existing brands. The compnay has had a terrific track record in helping entrepreneurs avoid mistakes and improve their success rate in new product development.

\begin{abstract}
NEJE: Why is compressing the time for new product development so important for entrepreneurs?

Kaye: New entrepreneurial companies cannot afford the time, the money, or the failure. They have one time at bat, and must deliver-or their venture will fail.
\end{abstract}

\section{NEJE: What makes your process of developing new products different?}

Kaye: Basically, we have "restaged" the new product process (Exhibit 1) by challenging and changing every technique, system, and step that does not produce successful new products, that wastes time and money, and that increases the risk of failure. It demands the questioning of so-called "truths" of new product development which really are "myths." And it requires fundamentally changing the new products organization-from the roles and skills of individuals, teams, and top management to the ultimate decision-making process. Overall, there are many complex key steps to develop a successful new product or service.

\section{NEJE: How does the organization have to change?}

Kaye: In a typical, top-down organization, most CEOs manage their existing businesses by delegating tasks to subordinates who bring ideas, recommendations, and alternatives to them for decisions. Unfortunately, many CEOs and top managers use the same organization for new products and this can be a disastrous error. The result is that the toughest, trickiest creative task is given to junior people who may be talented, but who have minimal new products experience. No wonder most new products fail. They are doomed from the start!

To change these dynamics, we suggest entrepreneurs start by throwing out the traditional organization chart, and taking the following steps.

1. Create teams that take advantage of top management's experience by including them from the beginning as team members. They need not come to every meeting, but they should help set objectives for the overall program and attend meetings involving key decisions and milestones.

2. Choose a leader with experience and passion for the project so that he or she will be a true "champion" and inspire the team. The leader must see the project through from beginning to end and fight to retain its integrity. One of the fundamental mistakes companies make is "changing horses in mid stream." A new leader or team will challenge and want to change'the program. Usually this results in failure.

3. Hire a new product creative consultant who can coach the team, provide leadership, and be another champion for the idea. Ideally, you should get a complete creative resource that provides ideas, concepts, names, packaging, focus groups, and positioning.

\footnotetext{
NEJE: Won't there be resistance to these kinds of changes?

Kaye: Yes, there's always that chance, but the entrepreneur has to weigh the benefits of changing the organization and having to convince folks this system will work. Without these changes, entrepreneurs will simply repeat the mistakes of their colleagues and face the same kind of high failure rates of the past.
} 


\section{Exhibit 1}

Traditional vs. Warp Speed New Product Development Program

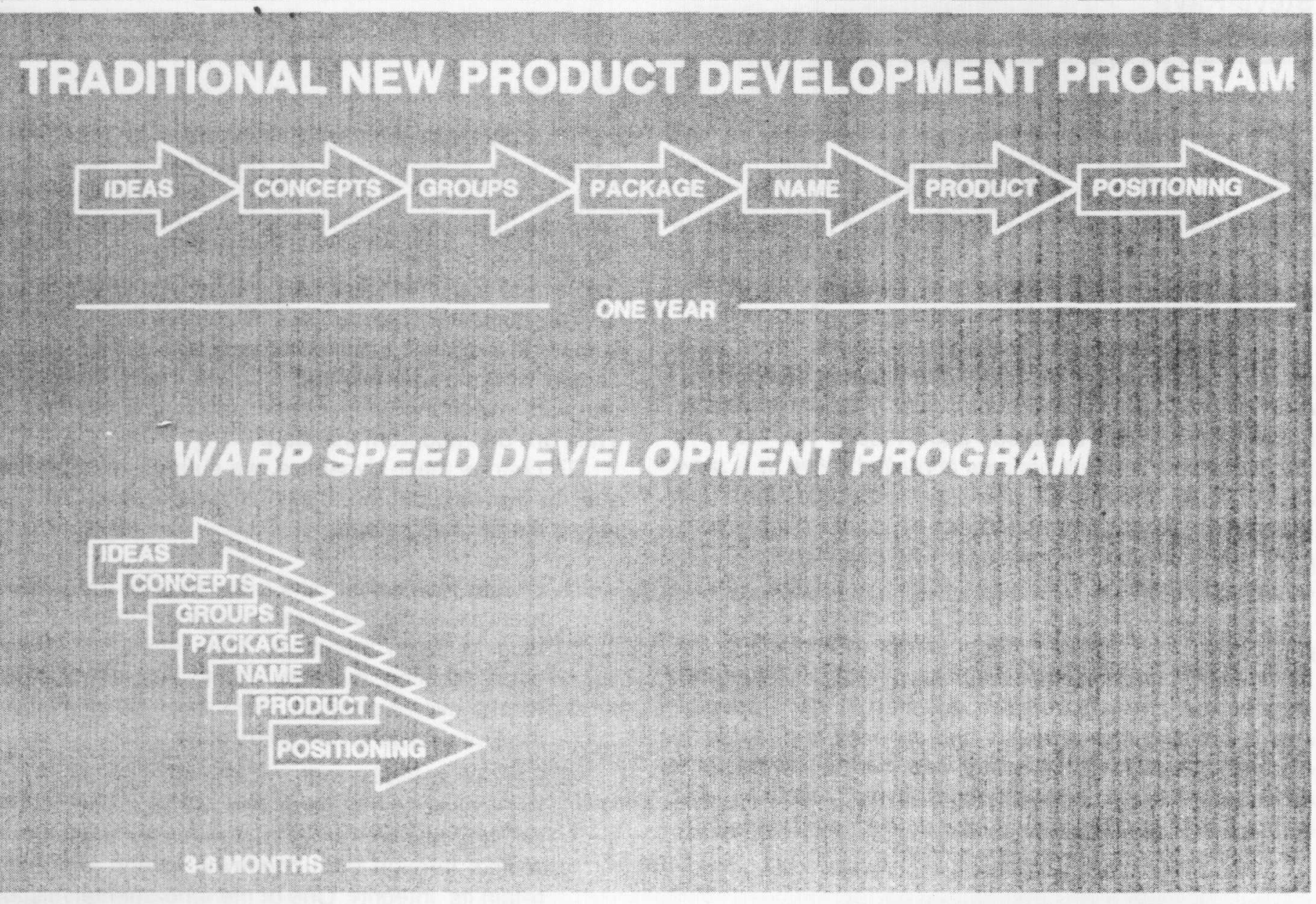

\section{NEJE: Are there some specific things to avoid?}

Kaye: Absolutely! There are two key assumptions that must be avoided.

First, don't assume that the advertising agency can provide new product experience or creativity. Usually they don't make money on this work and will assign junior account people instead of creative writers and art directors.

Second, don't assume that the market research department or quantitative market research can help develop ideas. They usually can't. Use structured market research only to evaluate ideas, not to create them.

\section{NEJE: What's next?}

Kaye: Creating the one really big idea. The secret to creating one great idea is to develop a huge number of ideas. Then, put them into finished concepts (print ads, packages, websites, etc.) and show them to consumers. However, there are potential idea traps that could get in the way of successful product development. Here are a couple:
- Beware of working with a small number of concepts. They could all be weak, and consumers could be choosing the best of bad concepts.

- Most brainstorming generates long lists of incomplete ideas on easel pads. It is usually a waste of time unless the work is followed up with a disciplined process to optimize the best concepts.

\section{NEJE: Okay, now you have lots of concepts. Then} what?

Kaye: After ideas have been generated, the next step is to articulate them into concepts. There has been much controversy over what a concept actually is, and the difference between good and bad concepts. Our definition of a good concept is:

A combination of real-world stimuli that fully explain the idea, including all benefits (physical and emotional) and attributes, and that appeal 
to the senses (taste, smell, etc.). It should show potential users and the product or service in actual use.

The key to good concepts is to make them as close to the real world as possible. We call them Visualideation ${ }^{\mathrm{TM}}$ concepts. They are concepts that are complete, visualized print ads, with "tight" packages containing all the information the consumer will see on the shelf (including price and usage). The secret: Make them look real!

\section{NEJE: Please explain that.}

Kaye: For nonconsumer products, ideas should be executed in the actual medium that would be used to market them. Websites should be pretested on-line, to make sure that all of the interactive links are understandable, logical, and easy to use.

To get consumer reaction in focus groups or in one-onone research, it is important to develop many concepts in three categories:

1. A variety of ways to "sell" the ideas

2. Diagnostic concepts to explore key issues

3. Competitive advertising to be translated into concept format to measure vulnerability to competition

NEJE: What about the "traps" you mentioned earlier? Kaye: I can think of two extremely important ones.

First, don't use "Concept Statements" on white cards. It is critical to visualize ideas because that is how consumers see them in real-world advertising

Second, don't be confused by the argument: "We won't know which is communicating - the visuals or the words." That is nonsense. In the real world, consumers see ads, commercials, and packages as both visuals and words

\section{NEJE: And focus groups are next.}

Kaye: Yes, focus groups are a critical step in new product development. Some of the secrets of getting the most from them, leading to unique, competitive ideas that will be winners in the marketplace include:

- Show a large number of Visualideation concepts. This simulates the real world in which consumers are bombarded with print ads, TV commercials, and products at the store shelf.

- Recruit "creative consumers." There are many techniques for doing this. Two of the best are:

1. Get consumers who have been to groups before, are comfortable in a focus group situation, and are known to be creative (available from the facility's database)

2. Ask them questions in the screening questionnaire requiring creative thinking.
- Use a moderator who specializes in new products and idea development. In our group, the moderator is a copywriter, new product and marketing expert who can build on consumer ideas.

- Use a variety of techniques to stimulate consumer creativity and optimize the ideas. Some examples:

- Ask for unaided recall, forcing consumers to "remember" the best ideas.

- Ask consumers to write ads and package copy.

- Use a summary "Benefit Probe" list which explores all the potential benefits of each idea.

- Use humor. Make the group fun-this is a critical ingredient in getting consumers to relax and be creative.

\section{NEJE: Any advice for what not to do with focus groups?}

Kaye: From long experience I can tell you don't recruit people who have never been to groups before. They may not show up, don't talk as much, and usually aren't very creative. Don't try to over analyze a concept, word by word. In the real world, consumers spend very little time studying a product (a minute or less).

Also, don't use inexperienced, low-cost moderators. Less-qualified moderators will typically miss many opportunities by failing to recognize meaningful comments. In addition, you should not involve your own staff as moderators. They will typically have an agenda and that will bias your research results.

\section{NEJE: What about the product's packaging? When does that piece come in?}

Kaye: Packaging is a critical part of a new product. You should always try to create a unique form that will separate your product from the competition. Great examples are the new Apple iMac computer and the WW Beetle.

The package copy is also critical, especially if there will be minimal advertising. Think of the package as an advertisement with the front panel the headline, and the rest of the package as the body copy.

Package ideas should be created very early, so they can be shown to consumers in groups, along with concepts. A key step in groups is to ask consumers to write package copy and to pick the visuals that best fit the idea.

\section{NEJE: And the timing?}

Kaye: Don't delay packaging work until the end of the process. Do it concurrent with the concept boards. Ideally, your new product consultant/agency should have a strong package design capability, so you can avoid "changing horses in midstream"-One of the major new products killers l've seen over the years. Don't believe the package designers that tell you it takes eight weeks and endless meetings to design a package. We do it in two to three weeks. 
NEJE: We haven't discussed brand name generation yet. When does that occur?

Kaye: Names are critical to a brand's success, so it is important to create a name that telegraphs what the brand's benefits ale. We create a large number of names at the beginning of the project. They are executed into logos, used on concepts, and tested in groups.

When you begin the project, a review the company's trademark list. Frequently, there are good names of which the client is not aware. This is key, because it bypasses the tedious process of searching and clearing a new mark. We also ask for the trademarks registered in the category. Often they are available through disuse or abandonment.

\section{NEJE: Any pitfalls to avoid with brand name genera-} tion?

Kaye: Sure. Don't test concepts without names or with disguised names. Consumers will be confused and give you the wrong answers. And don't limit yourself to oneword names. Use tag lines and product descriptors along with the primary name for a fuller explanation.

\section{NEJE: What about a critical next step like developing prototypes?}

Kaye: My advice to entrepreneurs is to develop and test prototypes early. Ultimately, the product is the most important element in the process. If a food product doesn't taste good, or other products don't work or deliver on their promise, the business will fail. A dramatic example was Crystal Pepsi, which was conceptually confusing and many thought it didn't taste good.

We test product ideas very early, in the first round of groups, using existing products and prototypes. We also place products in homes, so consumers can use them in a normal setting before they come to groups. At groups, it's important to show products to be sure they look right and are the correct sizes, portions, and flavors.

For nonfoods, consumers should be allowed to try the products to see if they function properly. Inevitably, we find a way to improve on early designs.

\section{NEJE: We've got a hunch you've got some sugges- tions on what to avoid.}

Kaye: After 35 years in the business, you bet 1 do. Don't do concept work without the product. Consumers may like an idea, but hate the product. It's critical to find this out as early as possible. With food, make sure that the product and flavors are described in a way that is appetizing. With websites, make sure that all steps are intuitive and simple.

NEJE: We learned in marketing that positioning the product vs. your competition is critical.

Kaye: No question. All of the elements above must ulti- mately fit into an internally consistent positioning statement. This is a guide for all advertising, package design, and promotion materials. When we positioned the original Huggies, the final positioning statement was as follows:

To moms with kids in diapers (Target Group), Huggies (Brand Name) Is the Disposable Diaper (Frame of Reference) That doesn't leak (Benefit) Because the legs are elasticized (Support).

Once you have a positioning statement, make sure all communication follows it without exception. There are problems one can experience here as well. The advertising agency doesn't follow the positioning statement, and creates ideas that really don't tell the right story. Also, sometimes the sales promotion effort at the store level doesn't fit with the advertising story. This can be a real problem because it can really confuse the consumer.

NEJE: All of this sounds helpful, but most new products face a steep uphill battle to become successful. Entrepreneurs still face long odds even with your different take on how to develop new products. How come?

Kaye: I'm asked that all the time. I hope you don't mind, but I will put it in list form because I've written down my favorite 25 potential pitfalls. Any single one of these can doom a project for the entrepreneur. When two or more of these occur on the same product development project, you can expect a disaster. So here's my list of 25 reasons why new products fail:

1. No champion to push the project along

2. No compelling consumer benefit

3. Benefit is not communicated well or enough

4. Poor product quality

5. In the food industry, the product doesn't taste or look good

6. Bad packaging

7. Changing horses in midstream

8. Development by committee

9. Inexperienced people running the project

10. Incorrect understanding of the consumer

11. Bad advice from new product consultant

12. Lack of management support

13. Incorrect use of the ad agency

14. Incorrect use of market research

15. Incorrect use of R\&D

16. Pricing too high

17. Lack of competitive insulation

18. Test program not translated to expansion

19. Neglect by sales force

20. Poor shelf location

21. Lack of distribution 
22. Competition is bigger, smarter, tougher

23. Hesitation ... Ready, Aim, Don't fire

24. Recklessness ... Ready, Fire, Aim

25. Product doesn't translate to other countries

\section{NEJE: Any final words?}

Kaye: Most entrepreneurs somewhere along the way realize their instincts and energy that inspired their idea are usually not enough for long-term marketing success. What makes entrepreneurs successful in starting up their business may not always be the same set of tools they require to see a project through from initial ideation to commercialization and a national (or global) roll-out.

So, while it may be humbling, the entrepreneur should seek out a marketing professional to oversee the productdevelopment process. It can pay big dividends in the end. 